\title{
A Comparison of Equatorial Electrojet in Peru and East Brazil
}

\author{
R.G. Rastogi ${ }^{1}$, H. Chandra ${ }^{*}, 1$, Rahul Shah ${ }^{1}$, N.B. Trivedi ${ }^{2}$ and S.L. Fontes ${ }^{3}$

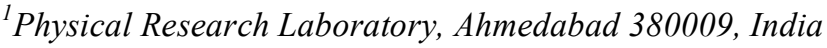 \\ ${ }^{2}$ National Institute of Space Research, Sao Jose dos Campos, Brazil \\ ${ }^{3}$ Observatario Nacional - ON/MCT, Rio de Janeiro, Brazil
}

\begin{abstract}
The paper describes the characteristics of the equatorial electrojet at Huancayo (HUA, $12.1^{\circ} \mathrm{S}, 75.3^{\circ} \mathrm{W}$, inclination $1.5^{\circ} \mathrm{N}$, declination $1.0^{\circ} \mathrm{E}$ ) in western side of South America, where the geomagnetic field is aligned almost along the geographic meridian, and at Itinga (ITI, $4.3^{\circ} \mathrm{S}, 47.0^{\circ} \mathrm{W}$, inclination $1.4^{\circ} \mathrm{N}$, declination $19.3^{\circ} \mathrm{W}$ ) in eastern part of South America, where the geomagnetic field is aligned about $19^{\circ}$ west of the geographic meridian; although the mean intensity of the magnetic field in the two regions are almost of the same order. Further comparisons are made of the current at Itinga and at Tatuoca (TTB, $1.2^{\circ} \mathrm{S}, 48.5^{\circ} \mathrm{W}$, inclination $7.8^{\circ} \mathrm{N}$, declination $18.7^{\circ} \mathrm{W}$ ), a low latitude station in the same longitude sector. The daily range of horizontal component of the geomagnetic field, $\mathrm{H}$, is shown to be almost $16 \%$ higher at HUA compared to that at ITI. The daily variation of the eastward field, Y, showed a strong minimum of $-40 \mathrm{nT}$ around 13-14 hr LT at ITI whereas very low values were observed at HUA with a positive peak of about $4 \mathrm{nT}$ around 11$12 \mathrm{hr}$ LT. The vertical field, Z, showed abnormally large negative values of -70 $\mathrm{nT}$ at TTB around $13 \mathrm{hr}$ LT. The day-today fluctuations of midday and midnight values of $\mathrm{X}$ field were positively correlated between HUA and ITI with a high correlation coefficient of 0.78 and 0.88 respectively. Values of $\mathrm{Y}$ field were also significantly positively correlated between HUA and ITI for midnight hours (0.72), while no correlation was observed for the midday hours. The midnight values of X field at HUA, ITI and TTB showed significant ( 0.90 or greater) correlation with Dst index. Correlation values of about 0.7 were observed between Dst and midday values of X at ITI and TTB and to a lesser degree (0.4) at HUA.
\end{abstract}

Keywords: Equatorial electrojet, equatorial E-region, geomagnetism.

\section{INTRODUCTION}

The most important discovery which has revolutionized the basic idea of low latitude ionospheric current system had been the result of the ground magnetic survey by Giecke (only quoted by Chapman [1]) at fourteen stations in Peru during the period September to November 1949. The daily range of the horizontal geomagnetic field, $\mathrm{H}$, was found to increase from $7^{\circ}$ geographic latitudes to a peak at $13^{\circ} \mathrm{S}$ (close to the magnetic dip equator) with a ratio of 2. Chapman [1] interpreted the result as due to a narrow band of thin current sheet flowing eastward during day time hours in the ionosphere and named as equatorial electrojet (EEJ).

This sudden increase in the daily range of $\mathrm{H}$ near magnetic equator (Huancayo anomaly) presented a serious problem to the Chapman [2] current system which was derived from data at only middle latitudes, now requiring abnormally large local wind velocities to generate a large electro motive force for the EEJ. This problem was solved by Baker and Martyn [3] who pointed that near the magnetic equator the geomagnetic field, electric field and the vertical electron density gradient are orthogonal to each other. At the magnetic equator the direction of current flow during the day

*Address correspondence to this author at the Physical Research Laboratory, Navrangpura, Ahmedabad 380 009, India;

Tel: +91-79-2631-4556; Fax:+91-79-2631-4900;

E-mails: hchandra@prl.res.in,hchandra44@gmail.com time is eastward and the magnetic field is northward. The electrons within $70-140 \mathrm{~km}$ altitude drift upward relative to the ions causing a vertical Hall polarization field, which increases the eastward Cowling conductivity. They also explained that beyond $3^{\circ}$ north or south from the magnetic equator, the polarization field leaks away along the inclined magnetic field and thus the abnormal conductivity is restricted to $\pm 3^{\circ}$ dip latitudes. Thus, the Sq electric field extended from low to equatorial latitudes was shown to be sufficient to generate the large equatorial electrojet current. Equatorial electrojet has been extensively studied from ground, rocket and satellite based magnetometers, spaced receiver drift, VHF backscatter radar and theoretical studies [4-6].

Rastogi [7] showed that the magnitude of EEJ is most pronounced in American zone and least in Indian zone. He suggested an inverse relationship between the equatorial conductivity and the background magnetic field in the environment. Model calculations have been made of EEJ [811]. Richmond [12] developed a numerical model including winds and instabilities and showed that the two-stream instability limits the strength of the polarization electric field and the eastward current. Increase in magnetic field strength reduces the Pedersen and Hall conductivities at all levels and also lowers the altitude of maximum polarization field to a level where Hall conductivity is lower thus reducing the electrojet strength. Gangepain et al. [13] compared different models and showed that differences arise largely due to 
different values of electron collision frequencies used. By empirically adjusting the electron collision frequency it was shown that a value that is four times that calculated from laboratory data correctly modeled the electrojet parameters. Ronchi et al. [14] examined how fully developed strongly turbulent state of the small-scale waves (tens of meters size) affects the large-scale dynamics. Adding the additional mobility and diffusion and the small wave-length density fluctuations from in-situ rocket measurements made from Peru it was shown that the equilibrium vertical electric field peaks around $100 \mathrm{~km}$ in absence of turbulent terms and around $105 \mathrm{~km}$ in presence of them. Peak value of the vertical polarization field also decreases in the presence of turbulent terms.

Ionospheric drift measurements from spaced receiver technique at Thumba showed a high correlation between drift velocity and electrojet strength as determined from the difference between the ranges in $\mathrm{H}$ at Trivandrum, near dip equator and Alibag, outside electrojet [15]. Thus in the absence of electric field measurements one can use electrojet strength as an index of the electric field in ionosphere (Eregion). Anderson et al. [16] showed quantitative relationship based on the Jicamarca incoherent scatter radar drift observations and magnetometer data at Canete and Piura in Peru. It was further demonstrated for the Philippine longitude sector [17]. Uozuumi et al. [18] have studied EEJ using MAGDAS/CPMN data at four stations Addis Ababa (AAB), Davao (DAV), Ancon (ANC) and Eusebio (EUS) and found that the mean night time (18-06 LT) value of the $\mathrm{H}$ shows variations like Dst and can be used as a proxy to Dst for real-time and long-term monitoring and defined it as EDst index.

It may be mentioned here that the role of abnormally large wind was shown to affect the daily variations of $\mathrm{H}$ at Huancayo on certain days by Bartels and Johnston $[19,20]$. They showed that the lunar variations in $\mathrm{H}$ were abnormally large at Huancayo, such that on certain days the $\Delta \mathrm{H}$ during the daytime hours decreases below the base nighttime values. Gouin and Mayaud [21] described the phenomenon as observed at Addis-Ababa and named it as counter electrojet.

Day-to-day variability of $\mathrm{SqH}$ at mid latitude has been described by Greener and Schlapp [22] who found the longitudinal spatial scale to be of the order of $2000 \mathrm{~km}$. James and Rastogi [23] have described day-to-day fluctuations in $\mathrm{H}$ field at 13 stations along Indo-Russian longitude sector and found regions of high correlation among themselves: one equatorial region, second low latitudes equatorward of $\mathrm{Sq}$ focus and the third at mid latitudes north of $\mathrm{Sq}$ focus. Rastogi et al. [24] studied the day-to-day fluctuations in the daily range of $\mathrm{H}$ at the EEJ stations, Ancon (ANC) in Peru (77.6 W) and at Sao Luis (SLZ, 44.2 ${ }^{\circ}$ W) during the period January-June 1993. Regardless of the month, the range of $\mathrm{H}$ was significantly larger at ANC than at SLZ. There was excellent correlation in the daily range of $\mathrm{H}$ at the two stations.

Features of EEJ for different longitude sectors have been described for $75^{\circ} \mathrm{W}$ by [25]; for $15^{\circ} \mathrm{E}$ [26]; for $75^{\circ} \mathrm{E}[27,28]$; for $60^{\circ} \mathrm{W}$ [29] and for $45^{\circ} \mathrm{W}$ [30-33]. Rastogi and Trivedi [31] have described the profile of EEJ current system in the East Brazilian region. The most important feature of the geomagnetic field in this region has been that the horizontal field vector deviates by about $20^{\circ}$ westward of the geographic north. Thus very large westward component of the field was observed compared to geomagnetic field in the western part of South America where it is directed almost towards the geographic north. Kane and Trivedi $[34,35]$ compared equatorial electrojet at Huancayo in Peru and Eusebio in east Brazil. Shume et al. [36] have recently reported seasonal and longitudinal variability of the equatorial electrojet at Jicamarca and Sao Luis (East Brazil) for both solar maximum (2001-2002) and solar minimum (2007-2007).

\section{DATA}

A unique dense network of 26 three-axis fluxgate magnetometers were operated in East Brazil within the latitude $7.8^{\circ} \mathrm{S}$ to $4^{\circ} \mathrm{N}$ and longitudes $35^{\circ} \mathrm{W}$ to $49^{\circ} \mathrm{W}$ from November 1990 to March 1991. Digital fluxgate magnetometers measured vertical $(Z)$ and two orthogonal horizontal components of the geomagnetic field every minute with a resolution of $1 \mathrm{nT}$. The horizontal components were resolved to geographic north $(\mathrm{X})$ and east $(\mathrm{Y})$ using total horizontal field and the magnetic declination values of the stations. The maximum temperature changes of the fluxgate sensors were only $2-3^{\circ}$ during the period of observations so the temperature effects are negligible. Rigoti et al. [30] have described the characteristic of the EEJ from these data.

In this paper we present the features of the equatorial and low latitude current system in the eastern and western regions of South America based on comparison of the data from Huancayo, HUA $\left(12.1^{\circ} \mathrm{S}, 75.3^{\circ} \mathrm{W}\right.$, inclination $1.5^{\circ} \mathrm{N}$, declination $\left.1.0^{\circ} \mathrm{E}\right)$ with from Itinga, ITI $\left(4.3^{\circ} \mathrm{S}, 47.0^{\circ} \mathrm{W}\right.$, inclination $1.4^{\circ} \mathrm{N}$, declination $19.3^{\circ} \mathrm{W}$ ). Further to study the current system outside the EEJ we have compared data from ITI with that at Tatuoca, TTB $\left(1.2^{\circ} \mathrm{S}, 48.5^{\circ} \mathrm{W}\right.$, inclination $7.8^{\circ} \mathrm{N}$, declination $18.7^{\circ} \mathrm{W}$ ). The station code, geographic coordinates, geomagnetic inclination and declination angles at the locations are listed in Table 1. It is to be noted that the background geomagnetic field at both EEJ stations are almost same being about $28000 \mathrm{nT}$ but declination is $1.0^{\circ} \mathrm{E}$ at Huancayo and $19.3^{\circ} \mathrm{W}$ at ITI. The distance between the two stations is $28^{\circ}$ in longitude ( 1.9 hours) or about $2000 \mathrm{~km}$.

Table 1. Geographic Coordinates and Magnetic Parameters of the Stations

\begin{tabular}{|c|c|c|c|c|c|}
\hline Name & Code & Geog. Lat & Geog. Long & Inclination & Declination \\
\hline \hline Tatuoca & TTB & $1.2 \mathrm{~S}$ & $48.5 \mathrm{~W}$ & $7.8 \mathrm{~N}$ & $18.7 \mathrm{~W}$ \\
\hline Itinga & ITI & $4.3 \mathrm{~S}$ & $47.6 \mathrm{~W}$ & $1.4 \mathrm{~N}$ & $19.3 \mathrm{~W}$ \\
\hline Huancayo & HUA & $12.1 \mathrm{~S}$ & $75.3 \mathrm{~W}$ & $1.5 \mathrm{~N}$ & $1.0 \mathrm{E}$ \\
\hline
\end{tabular}

We define various terms used in the analyses. $\Delta \mathrm{X}, \Delta \mathrm{Y}$ and $\Delta \mathrm{Z}$ are the deviations of the hourly mean at the local time from the corresponding values between 0000 and 0100 hr LT (with very low value of conductivity in night time one does not expect ionospheric currents). The direction of $\mathrm{H}$ vector $\theta^{\circ}=\operatorname{arc} \tan \Delta \mathrm{Y} / \Delta \mathrm{X}$ is measured positive east of geographic north. The disturbance ring current index, Dst 
have been downloaded from the website of WDC for geomagnetism in Kyoto. The period of study chosen is 23 November 1990 to 31 December 1990 for which the data were available at all the three stations. The average sunspot number during this period was 142 and the average Ap index was 8 . The Dst index were very low for most of the days except during the sudden commencement storm starting at 2330 UT on 26 November 1990 when its value dropped to more than $-100 \mathrm{nT}$. The average values therefore are not truly representative of the international quiet days but fairly close to the geomagnetic quiet conditions.

Rastogi et al. [33] made quantitative estimate of the standard error in mean $\frac{\sigma}{\sqrt{n}}$ and of the standard deviation $(\sigma)$ of $\Delta \mathrm{X}, \Delta \mathrm{Y}$ and $\Delta \mathrm{Z}$ at each hour at SLZ for the month of April 1993. The standard error in mean in $\Delta \mathrm{X}$ varied from around $8 \mathrm{nT}$ at noon to $5 \mathrm{nT}$ in the evening-midnight hours. The value of the standard error in mean in $\Delta \mathrm{X}$ was least in the midnight-morning hours (1-2 nT). The standard deviation was $40 \mathrm{nT}$ around noon and remained fairly high in the evening-midnight hours with values around $30 \mathrm{nT}$. The standard error in mean $\Delta \mathrm{Y}$ was maximum around noon with a value of about $5 \mathrm{nT}$. The standard deviation was also maximum around noon with a value of $23 \mathrm{nT}$ and decreased to 7-8 $\mathrm{nT}$ in the evening-midnight hours. The high values of the standard deviations at noon are partly because of the dayto-day variability in the electrojet. Based on the mean values and standard errors in mean of $\Delta \mathrm{X}$ and $\Delta \mathrm{Y}$ at SLZ, the errors in the direction of $\mathrm{H}$ vector were computed. Error was very small (about a degree) between $09 \mathrm{~h}$ to $15 \mathrm{~h} \mathrm{LT}$. The error is very high between sunset and sunrise hours due to low values of the deviations in $\Delta \mathrm{X}$ and $\Delta \mathrm{Y}$ because of very low value of conductivity. For the present data set of duration of about a month the errors will be of similar order.

\section{RESULTS AND DISCUSSION}

\subsection{Mean Daily Variations of $\Delta \mathbf{X}, \Delta \mathbf{Y}, \Delta \mathbf{Z}$ and $\boldsymbol{\theta}$}

The mean daily variations of $\Delta \mathrm{X}, \Delta \mathrm{Y}, \Delta \mathrm{Z}$ and $\theta$ at the three stations are shown in Fig. (1a, b). The $\Delta \mathrm{X}$ was maximum of $128 \mathrm{nT}$ around $11 \mathrm{~h} \mathrm{LT}$ at HUA, $104 \mathrm{nT}$ at $12 \mathrm{~h}$ LT at ITI and $66 \mathrm{nT}$ at $12 \mathrm{~h} \mathrm{LT}$ at TTB. The value of $\Delta \mathrm{H}$ obtained from $\Delta \mathrm{X}$ and declination was $110 \mathrm{nT}$ at ITI and thus it is important to note that the range of $\mathrm{H}$ is about $16 \%$ higher at Huancayo than at Itinga, inspite of the main magnetic field $(\mathrm{H})$ same at the two stations. Stronger electrojet currents in western region than the eastern region of South America may arise from stronger electric field and/or higher conductivities. The range of $\mathrm{H}$ at Tatuoca was $60 \mathrm{nT}$ compared to $104 \mathrm{nT}$ at Itinga, because it is outside the EEJ belt. Kane and Trivedi [34-35] compared the equatorial electrojet at Huancayo in Peru and Eusebio in east Brazil and found electrojet stronger at Huancayo than at Eusebio. Recently Shume et al. [36] have reported seasonal and longitudinal variability in the equatorial electrojet at Jicamarca in Peru and Sao Luis in east Brazil during solar maximum (20001-2002) and solar minimum (2006-2007). The equatorial electrojet was stronger in the west coast than in the east coast for both solar maximum and solar (a)

\section{November - December, 1990}

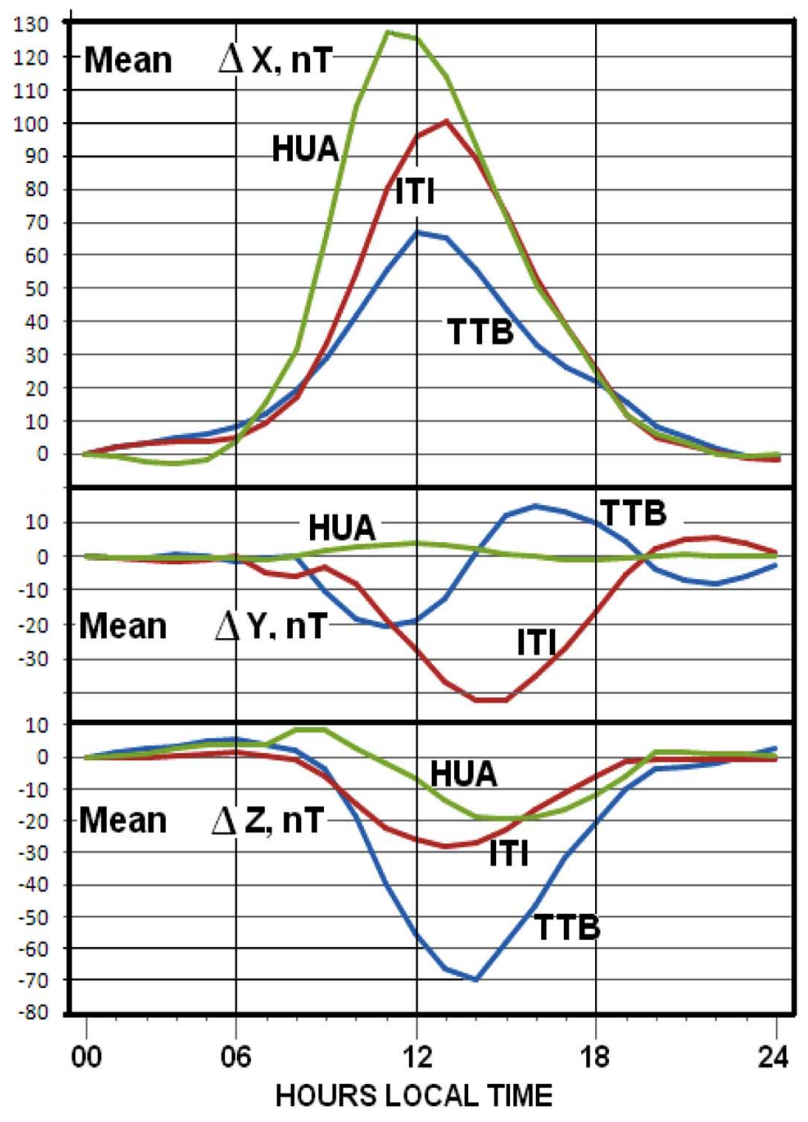

(b)

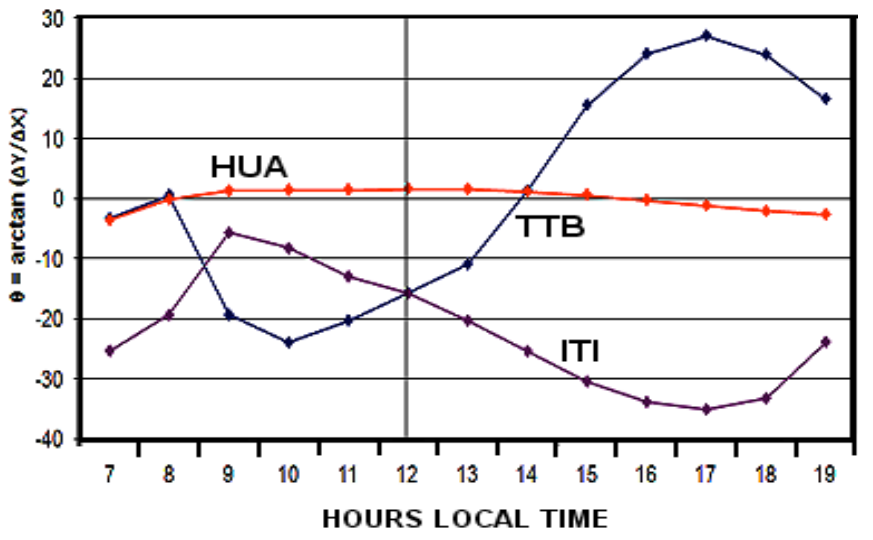

Fig. (1). Daily mean variations of (a) the deviations in $\mathrm{X}, \mathrm{Y}$ and $\mathrm{Z}$ components at HUA, ITI and TTB and (b) the direction of the horizontal vector $\mathrm{H}$ over HUA, ITI and TTB averaged over the period 22 November - 31 December 1990.

minimum. Seasonally while equatorial electrojet shows equinoctial peaks at Jicamarca there is maximum during December-January at Sao Luis. The observed seasonal difference was suggested to be likely due to the large declination at Sao Luis. It was also shown that the magnitude of the seasonal and solar cycle variability is more pronounced at Sao Luis than at Jicamarca.

The value of $\Delta \mathrm{Y}$ showed a peak of about $4 \mathrm{nT}$ at $11 \mathrm{~h} \mathrm{LT}$ at HUA but minimum value of $-40 \mathrm{nT}$ at 13-14 h LT at ITI. 
$\Delta \mathrm{Y}$ at TTB showed a minimum of $-20 \mathrm{nT}$ in the forenoon and maximum of $+18 \mathrm{nT}$ in the afternoon, a characteristic of December solstices [37].

The daily variation of $\Delta Z$ showed a large midday afternoon minimum at each of the stations. The magnitude of $\Delta \mathrm{Z}$ at TTB was very large as the station lies close to the northern fringe of the EEJ belt, in accordance to the Chapman's [1] model of the equatorial electrojet.

The direction of $\mathrm{H}$ vector $(\theta)$ at HUA was about $-3^{\circ}$ after sunrise, rose to $+2^{\circ}$ around noon and decreased to $-2^{\circ}$ by the evening hours. The direction of $\mathrm{H}$ vector at ITI was negative throughout the day varying from $-25^{\circ}$ in the morning to $-6^{\circ}$ at $08 \mathrm{~h} \mathrm{LT}$ and thereafter steadily reaching to $-35^{\circ}$ at $15 \mathrm{~h}$. The direction of the $\mathrm{H}$ vector at TTB was about $-20^{\circ}$ in the forenoon and $+30^{\circ}$ in the afternoon hours. There may be some contribution of field-aligned currents in $\Delta \mathrm{Y}$.

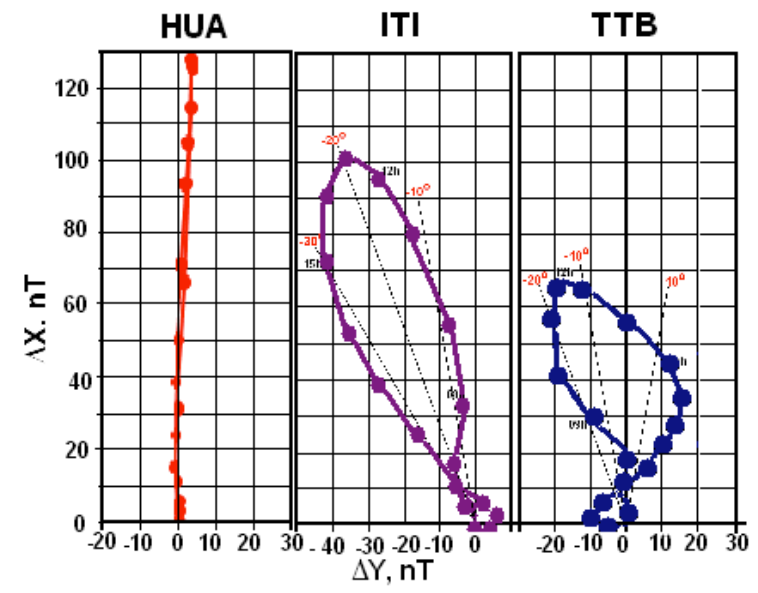

(a)

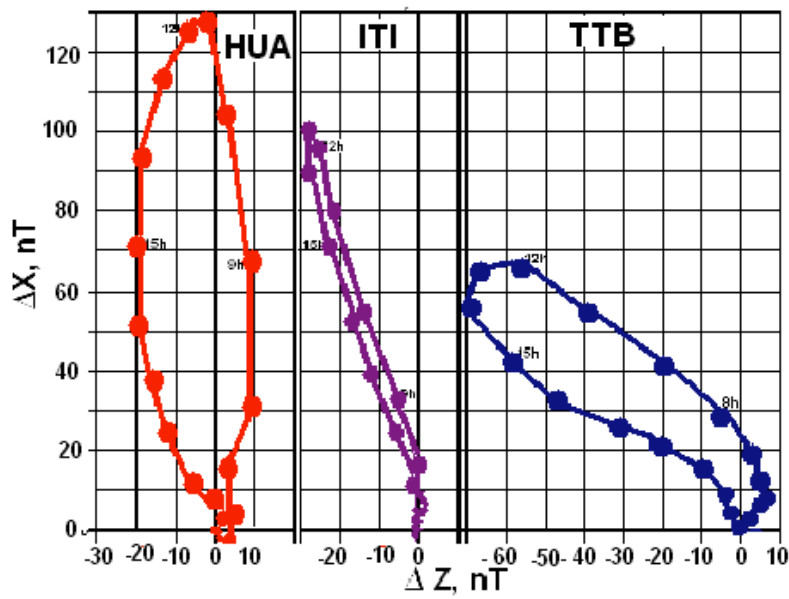

(b)

Fig. (2). (a) Hourly mean values of the deviations $\Delta X$ plotted as a function of $\Delta Y$ over HUA, ITI and TTB, (b) Hourly mean values of the deviations $\Delta \mathrm{X}$ plotted as a function of $\Delta \mathrm{Z}$ over HUA, ITI and TTB.

In Fig. (2a) are drawn the loops showing the simultaneous diurnal development of $\Delta \mathrm{Y}$ and $\Delta \mathrm{X}$ at HUA, ITI and TTB. The dashed lines indicate directions of regression lines (not shown for HUA where points lie along the line with direction of almost $0^{\circ}$ ). At HUA, $\Delta \mathrm{X}$ versus $\Delta \mathrm{Y}$ points show no tilt on the regression line suggesting that the current system is almost towards east in this region as expected of Chapman [1] model. At ITI the $\Delta \mathrm{X}$ versus $\Delta \mathrm{Y}$ points lie westward during the whole day suggesting a northward tilt of the current vector in this region due to large declination.

In Fig. (2b) are shown the simultaneous developments of $\Delta \mathrm{X}$ versus $\Delta \mathrm{Z}$ at different stations HUA, ITI and TTB. At HUA the loop is symmetrical along the geographic meridian suggesting the location of HUA to be very close to the centre of EEJ current belt. The broadening of loop suggests that HUA was shifted slightly southward of EEJ centre in the forenoon and northward in the after noon hours. At ITI the direction of $\Delta \mathrm{X}$ and $\Delta \mathrm{Z}$ loop indicate that the station was throughout the day shifted slightly north of the EEJ centre. The $\Delta \mathrm{X}$ versus $\Delta \mathrm{Z}$ loop at TTB was very much tilted due to its proximity of the EEJ belt.

\subsection{Daily Variation of $\Delta \mathbf{X}, \Delta \mathbf{Y}$ and $\Delta \mathbf{Z}$}

In Fig. (3) are shown the daily variations of $\Delta \mathrm{X}, \Delta \mathrm{Y}$ and $\Delta \mathrm{Z}$ for all the 37 days of observations respectively at the three stations (no data for 4 days at ITI). Corresponding variation of Dst index is also shown in the figure. Referring to Fig. (3c) the nighttime values of $\Delta \mathrm{X}$ at any of the stations

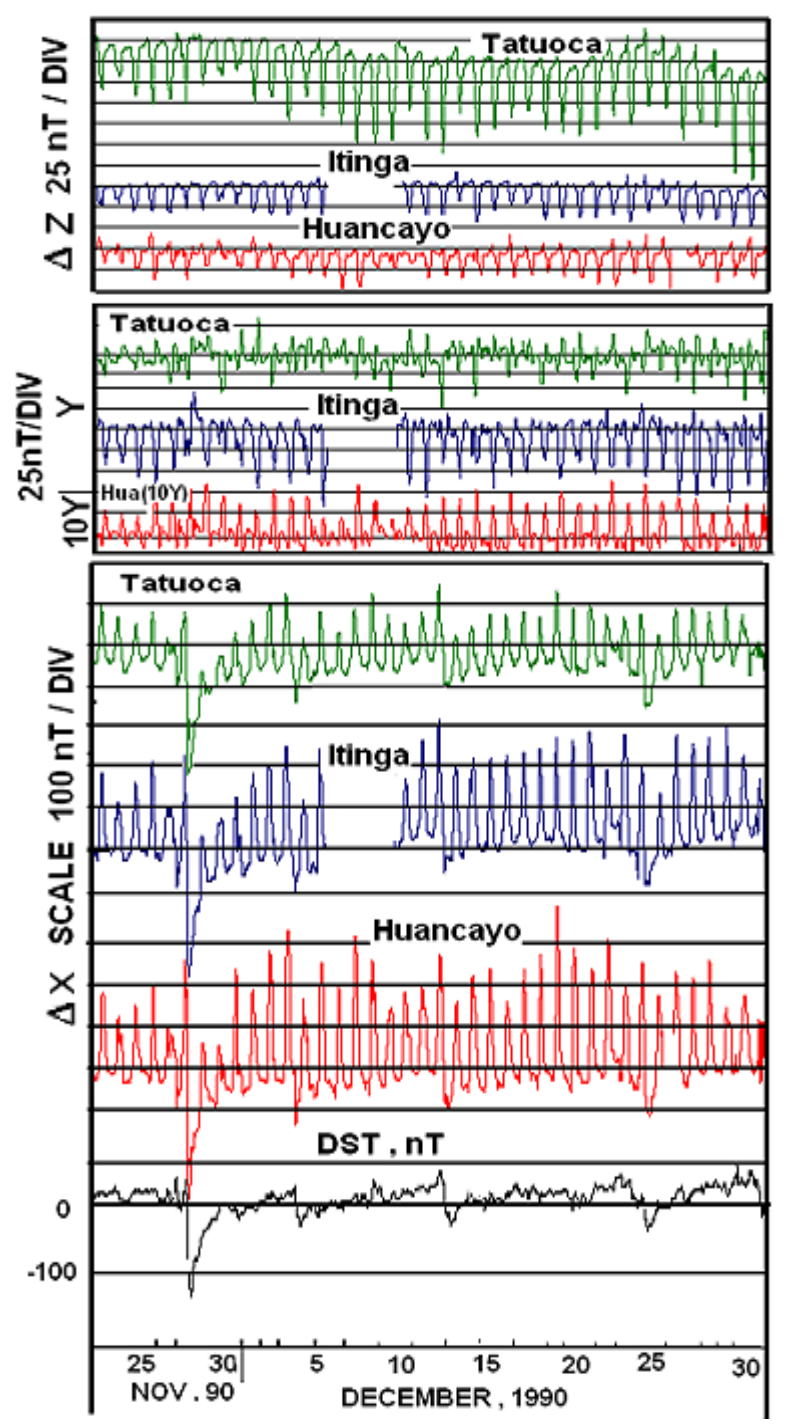

(a)

Fig. (3). Daily variations of (a) $\Delta Z$, (b) $\Delta Y$ and (c) $\Delta X$ for each day of the period 22 November-31 December 1990 at Tatuoca, Itinga and Huancayo. The variation of the Dst index is also shown. 
show correspondence with the variation of Dst index. This is expected as there are no ionospheric currents during night time and the changes are primarily due to ring current. The signature of the magnetic storms can be seen in the figure especially for the one on 27 November 1990 is very clear. There are large day-to-day variations of the midday value of $\Delta \mathrm{X}$ but definite associations between the different data sets are not very apparent.

Referring to Fig. (3b) showing the daily variations of $\Delta Y$ at these stations, large positive deviation at HUA, large negative deviation at ITI and both positive and negative deviations at TTB are seen. No apparent effect of the magnetic storm is apparent at HUA but $\Delta \mathrm{Y}$ at ITI and TTB show positive deviations during the storm.

Referring to the daily variations of $\Delta Z$ in Fig. (3a) at these stations, comparatively large negative deviations of $\Delta \mathrm{Z}$ are seen at TTB. No clear effect of Dst is seen.

\subsection{Correlation Between Fluctuations $(\Delta X, \Delta Y)$ at the Three Stations}

Next we checked correspondence between the midnight and midday values of $\mathrm{X}$ and $\mathrm{Y}$ at HUA and ITI. Deviations of $\mathrm{X}$ and $\mathrm{Y}$ were computed from overall mean value for midday and midnight hours at HUA and ITI. The mass plots of the deviations of $\mathrm{X}$ at HUA and ITI are shown in Fig. (4a). At midday, deviations in $\mathrm{X}$ at HUA are positively related to deviations in $\mathrm{X}$ at ITI with a correlation coefficient of 0.78 . The regression line has a slope of 0.68 . At midnight too, deviations in $\mathrm{X}$ at Huancayo are positively related to the deviations in $\mathrm{X}$ at ITI with correlation coefficient of 0.8 and the slope of regression line was 1.10. Thus the day-to-day changes of the ratio of $\mathrm{X}$ field at HUA to at ITI are 0.68 for the midday and 1.10 for midnight.

In Fig. (4b) are shown the mass plot of the deviations in $Y$ field at HUA versus the same at ITI for the midnight and midday hours. The deviations in Y at HUA plotted are 10 times the actual values. During midnight deviations in $\mathrm{Y}$ at HUA are positively correlated with the deviations in Y at ITI with correlation coefficient of 0.72 . During the daytime there is large scatter and no correspondences between the day-today changes of $\mathrm{Y}$ field at the two EEJ stations can be seen.

Correlations between the deviations of $\mathrm{X}$ and $\mathrm{Y}$ at HUA and ITI were computed for each of the hours. The daily variations of the correlation coefficient (blue lines) and of the slope of the regression line (pink line) are shown in Fig. $(\mathbf{5 a}, \mathbf{b})$ respectively. The correlation values between HUA (X) versus ITI $(\mathrm{X})$ range from about 0.94 to 0.54 . The correlation coefficient is 0.90 or more from about $15 \mathrm{~h}$ to 02 $\mathrm{h}$ LT. It decreases to 0.54 around $0830 \mathrm{~h} \mathrm{LT}$ and then rises slowly. The value of the slope is also lower between 0830 and $1430 \mathrm{~h} \mathrm{LT}$.

In Fig. (5b) are shown the daily variations of the correlation coefficient between HUA(Y) versus ITI (Y). It is to be noted that during midnight to morning $(00-06 \mathrm{~h} \mathrm{LT})$ the values of the correlation coefficient as well as of the slope of the regression line are between 0.6 and 0.9 . From $06 \mathrm{~h} \mathrm{LT}$ the values of the correlation coefficient and the slope of the regression line decrease rapidly with values of 0.0 at $0930 \mathrm{~h}$ $\mathrm{LT}$. The values increase then till $18 \mathrm{~h} \mathrm{LT}$ to 0.50 for correlation coefficient and 0.36 for the slope of regression line. The values show another sharp decrease to 0.0 at 2030 $\mathrm{h}$ LT and then increase to values of 0.50 at midnight. In general there is similarity in the daily variations of the correlation coefficients and slope of the regression lines between the deviations in $\mathrm{X}$ and $\mathrm{Y}$ at the two locations with minimum values around 0830-0930 $\mathrm{h} \mathrm{LT}$. Also the values are higher during night hours than day hours.

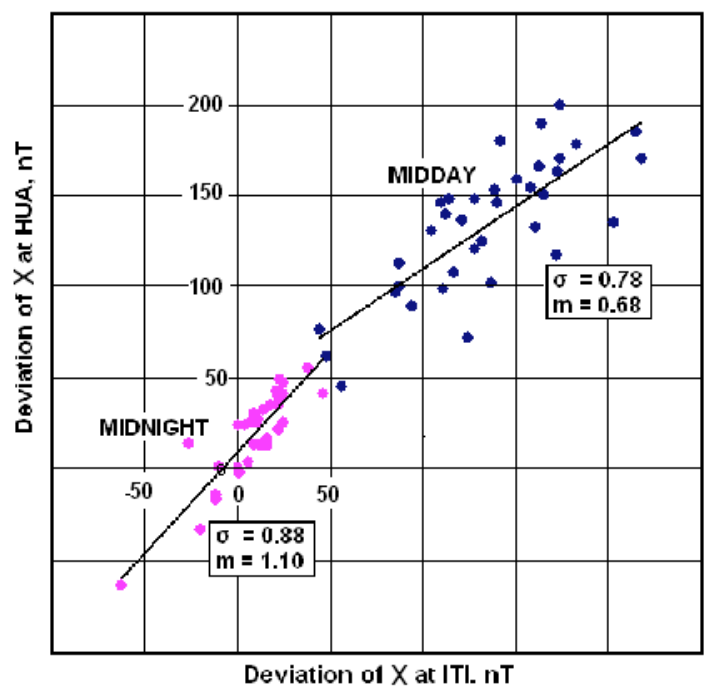

(a)

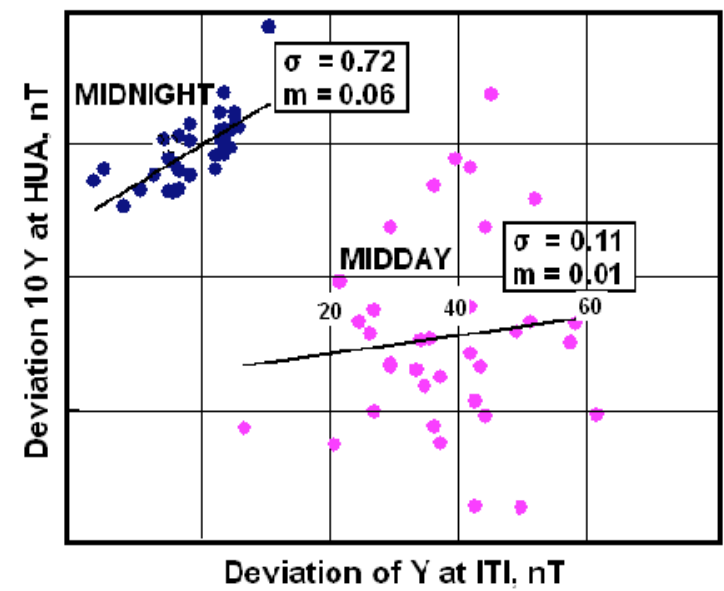

(b)

Fig. (4). (a) Scatter plots of the midday and midnight values of the deviations in $\mathrm{X}$ at HUA versus midday and midnight values of the deviations in $\mathrm{X}$ at ITI. The best-fit lines and the values of the standard deviations and slopes are also marked. (b). Scatter plots of the midday and midnight values of the deviations in Y (ten times) at HUA versus midday and midnight values of the deviations in $Y$ at ITI. The best-fit lines and the values of the standard deviations and slopes are also marked.

\subsection{Equatorial Electrojet and Disturbance Ring Current}

A comparison of the plots of $\triangle \mathrm{X}$ at HUA, ITI and TTB with the corresponding plots of Dst indicates a correlation between the equatorial $\Delta \mathrm{X}$ and Dst as expected. James et al. [38] have shown significant correlation between day to day fluctuations of $\Delta \mathrm{H}$ at the equatorial and mid latitude stations and corresponding Dst index for any time of the day.

In Fig. (6a) are shown the mass plots of $X$ field at $00.0 \mathrm{hr}$ LT (red dots) and $23.5 \mathrm{~h} \mathrm{LT}$ (blue dots) versus Dst index for the three stations. 

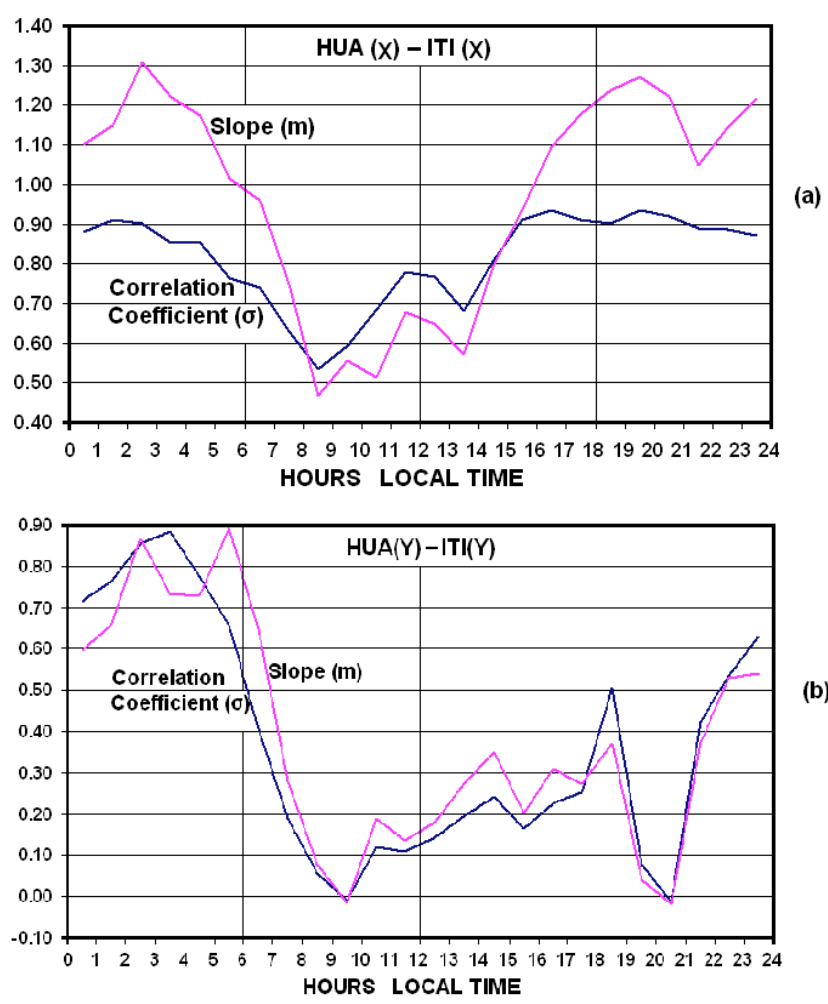

Fig. (5). The daily variations of the slopes of the best-fit line and the correlation coefficient between deviations in (a) $\mathrm{X}$ at HUA versus $\mathrm{X}$ at ITI and (b) $\mathrm{Y}$ at HUA versus $\mathrm{Y}$ at ITI.

There is a very high correlation between day-to-day fluctuations of night value of $\mathrm{X}$ field and Dst index with a correlation coefficient $0.9-1.0$ and the slope of around 1.0 at any of these stations. Thus it can be concluded that that the fluctuations in the night time values of $\mathrm{X}$ field at equatorial and low latitude stations are entirely due to the corresponding fluctuations of the ring current index. Uozuumi et al. [18] from MAGDAS/CPMN data at Addis Ababa (AAB), Davao (DAV), Ancon (ANC) and Eusebio (EUS) reported that the mean night time (18-06 LT) value of the $\mathrm{H}$ showed variations like Dst.

Fig. (6b) shows similar mass plots of $\mathrm{X}$ at $11.5 \mathrm{hr} \mathrm{LT}$ (blue dots) and $12.5 \mathrm{hr}$ LT (red dots) versus Dst index for the three stations. There are still positive correlations between midday $\mathrm{X}$ field and Dst index but the correlation coefficient values are low being 0.5 to 0.7 .

The hourly mean Dst index were subtracted from the corresponding hourly mean values of $\mathrm{X}$ at the three stations to obtain a purer index of ionospheric contribution, $\mathrm{X}^{*}$,

$\mathrm{X}^{*}=\mathrm{X}-\mathrm{Dst}$

The daily variations of $\mathrm{X}^{*}$ at HUA, ITI and TTB during the period 23 November to 31 December 1990, are compared with corresponding Dst index in Fig. (7a). It is seen that the night time fluctuations in $X$ (shown in Fig. 4c) are now gone, and the values of $X^{*}$ at any of the stations are fairly constant during the night time hours, in spite of the fluctuations of Dst during the same period.

In Fig. $(\mathbf{7 b}, \mathbf{c})$ are shown the daily variations of the maximum $\left(\mathrm{X}^{*^{\max }}\right)$ and minimum $\left(\mathrm{X}^{*^{\min }}\right)$ values of $\mathrm{X}^{*}$, respectively during the entire period for the three stations. It is very clear that the day-to-day variations of $\mathrm{X}^{*}$ at any station are now very well correlated with each other. The fluctuations are again seen to be larger at Huancayo than at Itinga. The fluctuations of minimum value of $\mathrm{X}^{*}$ at different stations are also seen to be well correlated.

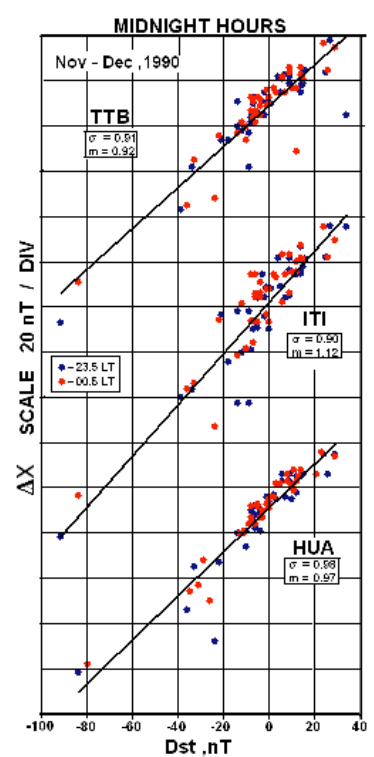

(a)

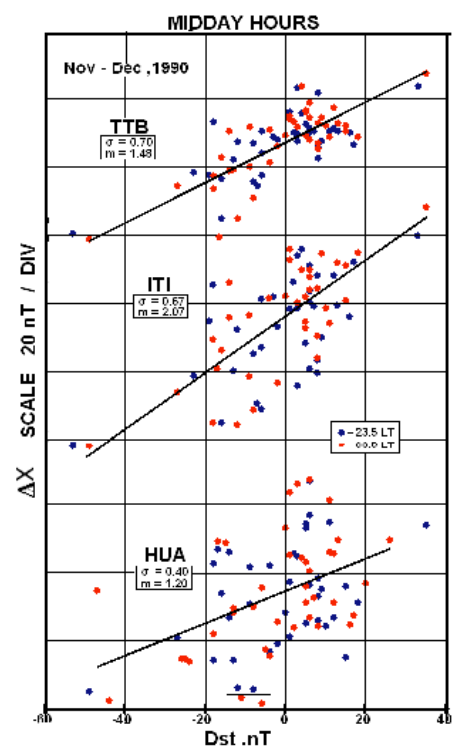

(b)
Fig. (6). Scatter plots of the deviations in $X$ versus Dst index for TTB, ITI and HUA (a) at midnight hours and (b) at midday hours.

In Fig. (8) are shown the mass plots of hourly values of $X^{*}$ at HUA and ITI separately for the maximum daily values $\left(X^{* \max }\right)$ and for the minimum daily values of $\left(\mathrm{X}^{* \min }\right)$ against the corresponding value at ITI. It is seen that $X^{* \max }$ at HUA are well correlated with $X^{* \max }$ at ITI with correlation coefficient of about 0.7 . The mass plot of $X^{* \text { min }}$ values at HUA and ITI almost overlap with good correlation of 0.80 between the two.

\section{CONCLUSION}

Characteristics of the equatorial electrojet at Huancayo (HUA) in western side of South America where the geomagnetic field is aligned almost along the geographic meridian and at Itinga (ITI) in eastern part of South America where the geomagnetic field is aligned about $19^{\circ}$ west of the geographic meridian are studied. The mean intensity of the magnetic field in the two regions are almost of the same order. Comparisons are also made of the current at Itinga and at Tatuoca (TTB), a low latitude station in the same longitude sector.

The daily range of horizontal component of the geomagnetic field, $\mathrm{H}$, is shown to be almost $16 \%$ higher at HUA compared to that at ITI. The daily variation of the eastward field, Y, showed a strong minimum of $-40 \mathrm{nT}$ around 13-14 hr LT at ITI whereas a positive peak of about 4 nT was observed at HUA around 11-12 hr LT. The vertical field, $\mathrm{Z}$ showed abnormally large negative values of -70 nT at TTB around $13 \mathrm{hr} \mathrm{LT}$.

The day-to-day fluctuations of midday and midnight values of $\mathrm{X}$ field were positively correlated between HUA and ITI with correlation coefficient of 0.78 and 0.88 
respectively. Values of $\mathrm{Y}$ field too were significantly positively correlated between HUA and ITI for midnight hours $(0.72)$ while no correlation $(0.11)$ was observed for the mid day hours.

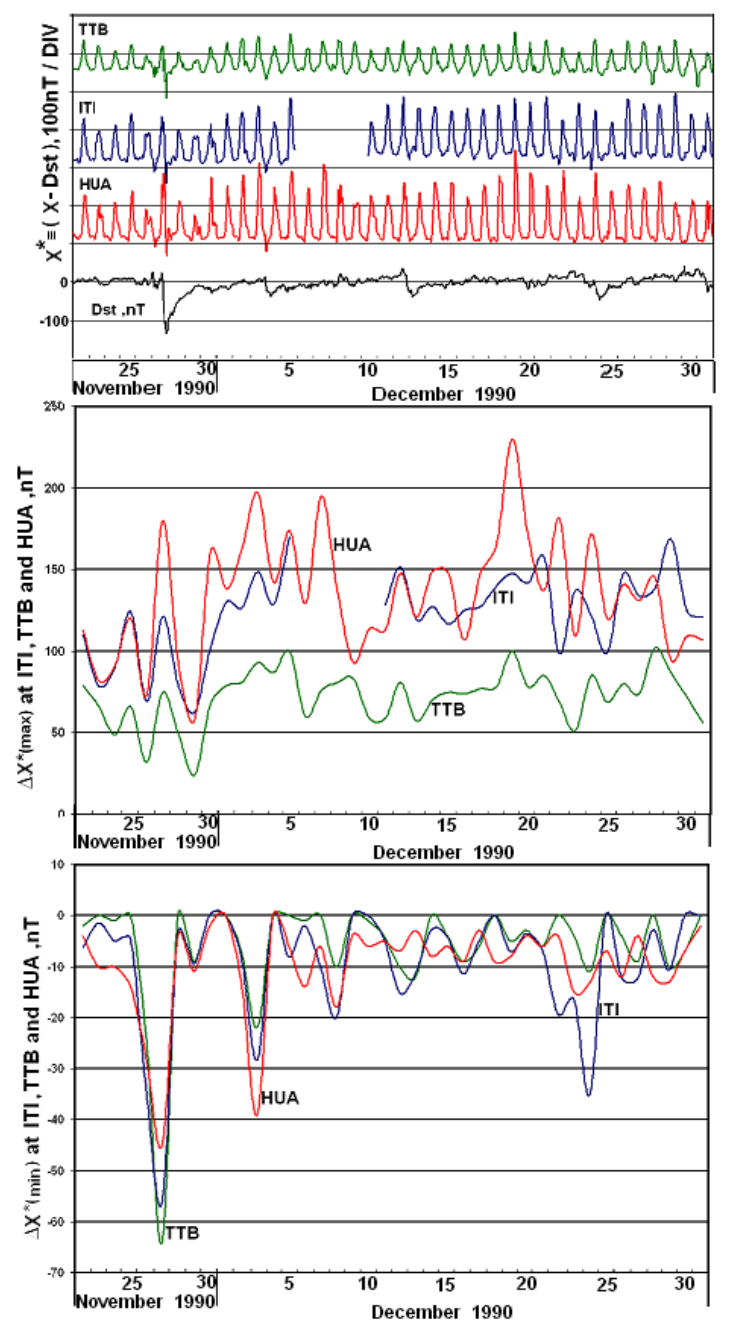

(a)

(b)

Fig. (7). (a) Daily variations of $X^{*}$, the deviations in $X$ after subtracting the Dst values, for each of days during the period 22 November -31 December 1990 at TTB, ITI and HUA. The Dst values are also plotted. (b) Day-to-day variations of $\mathrm{X}^{* \max }$, the maximum value of the deviations in $X$ after subtracting the Dst values, at HUA, ITI and TTB for the period 22 November-31 December 1990. (c) Day-to-day variations of $X^{* m i n}$, the minimum value of the deviations in $\mathrm{X}$ after subtracting the Dst values, at HUA, ITI and TTB for the period 22 November- 31 December 1990.

The midnight values of $\mathrm{X}$ field at HUA, ITI and TTB showed significant ( 0.90 or greater) correlation with Dst index. Correlation values of about 0.7 were observed between Dst and midday values of X at ITI and TTB and to a lesser degree (0.4) at HUA.

The ground geomagnetic field variations are assumed to be primarily due to the electric current in the ionosphere (Eregion), which itself is the combined effects of the neutral wind and electrical conductivity (ionization density). Due to the interaction of the solar wind with magnetosphere, there is always dusk to dawn electric field imposed on the ionosphere. In addition there are other currents namely magnetopause and magnetopheric tail currents affecting the ground magnetic measurements. Disturbance current which is always present even during the quiet days is additional source of magnetic field variation at ground. Thus there are complex sources of electric field imposed on the equatorial ionosphere besides the primary atmospheric dynamo electric field.
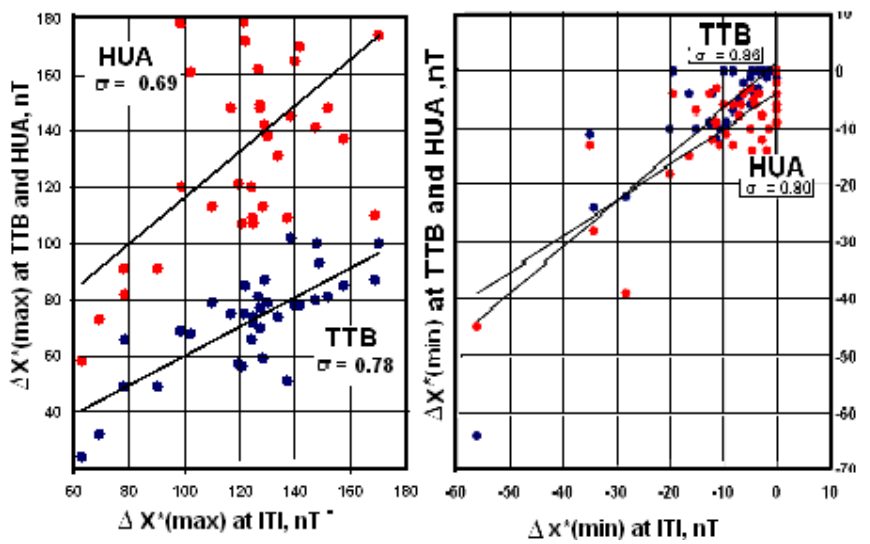

Fig. (8). Scatter plots of $X^{* \max }$, the maximum deviations in $X^{*}$, at HUA and TTB plotted versus $X^{* \max }$ at ITI (left panel) and of $X^{*^{* m i n}}$, the minimum deviations in $\mathrm{X}^{*}$, at HUA and TTB plotted versus $\mathrm{X}^{* \text { min }}$ at ITI (right panel).

\section{CONFLICT OF INTEREST}

The authors confirm that this article content has no conflict of interest.

\section{ACKNOWLEDGEMENTS}

Thanks are due to the Physical Research Laboratory, Ahmedabad for the infrastructure facilities and to the Indian Space Research Organisation, Bangalore for financial support during the analysis of the data. Thanks are also due to Prof. N.B. Trivedi of INPE for providing the data at ITINGA and to S.L. Fontes for the data at Tatuoca. The data at Huancayo were downloaded form the website of WDC for geomagnetism at Kyoto.

\section{REFERENCES}

[1] Chapman S. The equatorial electrojet as detected from the abnormal electric current distribution above Huancayo, Peru and elsewhere. Arch Meterol Geophys Bioklimatol 1951; A4: 368-90.

[2] Chapman S. The solar and lunar diurnal variations of terrestrial magnetism. Philos Trans Ray Soc 1919; A218: 1-118.

[3] Baker WJG, Martyn DF. Electric currents in the ionosphere 1, the conductivity. Phil Trans Roy Soc Lond 1953; A246: 281-94.

[4] Forbes JM. The equatorial electrojet. Rev Geophys Space Phys 1981; 19: 469-504.

[5] Reddy CA. The equatorial electrojet. Pure Appl Geophys 1989; 131: 485-508.

[6] Rastogi RG. The equatorial electrojet: magnetic and ionospheric effects in Geomagnetism. Jacobs J, Ed. USA: Academic Press 1989; vol. 3: pp. 461-525.

[7] Rastogi RG. Longitudinal variation in the equatorial electrojet. J Atmos Terr Phys 1962; 24: 1031-40.

[8] Suguira M, Cain JC. A model equatorial electrojet. J Geophys Res 1966; 71: 1869-77.

[9] Untiedt J. A model of the equatorial electrojet involving meridional currents. J Geophys Res 1967; 72: 5799-810.

[10] Sugiura M, Poros DJ. An improved model equatorial electrojet with a merional current system. J Geophys Res 1969; 74: 4025-34.

[11] Anandrao BG. Effects of gravity waves winds and wind shears on the equatorial electrojet. Geophys Res Lett 1976; 3: 545-8. 
[12] Richmond AD. Equatorial electrojet, I, Development of a model including winds and Instabilities. J Atmos Terr Phys 1973; 35: 1083-103.

[13] Gangepain J, Crochet M, Richmond AD. Comparison of equatorial electrojet models. J Atmos Terr Phys 1977; 39: 1119-24.

[14] Ronchi C, Sudan RN, Similon PL. Effect of short-scale turbulence on kilometer wavelength irregularities in the equatorial electrojet. J Geophys Res 1990; 95: 189-200.

[15] Chandra H, Misra RK, Rastogi RG. Equatorial ionospheric drift and the electrojet. Planet Space Sci 1971; 19: 1497-503.

[16] Anderson D, Anghel A, Yumoto K, et al. Estimating daytime vertical $\mathrm{E} \times \mathrm{B}$ drift velocities in the equatorial F-region using ground-based magnetometer observations. Geophys Res Lett 2002; 29: 1596, doi:10/1029GLO14562.

[17] Anderson D, Anghel A, Chau JL, et al. Global, low-latitude, vertical $\mathrm{E} \times \mathrm{B}$ drift velocities inferred from daytime magnetometer observations. Space Weather 2006; 4: S08003.

[18] Uozumi T, Yumoto K, Kitamura K, et al. A new index to monitor temporal and long-term variations of the equatorial electrojet by MAGDAS/CPMN real-time data: EE-Index. Earth Planet Space 2008; 60: 785-90

[19] Bartels J, Johnston HF. Geomagnetic tides in horizontal intensity at Huancayo 1. J Geophys Res 1940; 45: 269-308.

[20] Bartels J, Johnston HF. Geomagnetic tides in horizontal intensity at Huancayo 2. J Geophys Res 1940; 45: 485-592.

[21] Gouin P, Mayaud PN. A proposal for the possible existence of a counter electrojet at magnetic equatorial latitudes. Ann Geophys 1967; 23: 41-7.

[22] Greener JG, Schlapp DM. A study of day-to-day variability of Sq over Europe. J Atmos Terr Phys 1979; 41: 217-23.

[23] James ME, Rastogi RG. Critical study of the solar daily range of geomagnetic $\mathrm{H}$ field at Indo-Russian chain of Stations. J Indian Geophys Union 2002; 4: 187-94.

[24] Rastogi RG, Chandra H, Chakraborty D, et al. Day to day correlation of equatorial electrojet at two locations separated by 2000 km. Ann Geophys 2007; 25: 875-80.

[25] Forbush SE, Casaverde M. In Equatorial electrojet in Peru, Carnigie Instn. Washington Publ. No.620, Washington DC 1961
[26] Fambitakoye O, Mayaud PN. Equatorial electrojet and regular daily variations, SR 1. A determination of equatorial electrojet parameters. J Atmos Terr Phys 1976; 38: 1-17.

[27] Arora BR, Mahashabde MV, Kalra R. Indian IEEY geomagnetic observational program and some preliminary results. Rev Braz Geophs 1993; 11:365-85.

[28] Rastogi RG. Ionospheric current system in Indo-Russian longitude sector. Sci Cult 1999; 65: 269-82.

[29] Rastogi RG, Chandra H, James ME, et al. Characteritics of equatorial electrojet in the central region of South America. Earth Planet Space 2008; 60: 603-32.

[30] Rigoti A, Chamalan FH, Trivedi NB, et al. Characteristics of equatorial electrojet determined from an array of magnetometers in N-NE Brazil. Earth Planet Space 1999; 51: 115-28.

[31] Rastogi RG, Trivedi NB. Asymmetrics in the equatorial electrojet around N-E Brazil sector. Ann Geophys 2009: 27: 1-17.

[32] Denardini CM, Abdu MA, Aveirvo HC, et al. Counter electrojet features in the Brazilian sector. Simultaneous observation by radar, digital sounder and magnetometers. Ann Geophys 2009; 27: 1593603.

[33] Rastogi RG, Chandra H, Yumuto Y. Equatorial electrojet in East Brazil longitudes. J Earth Syst Sci 2010; 119: 497-505.

[34] Kane RP, Trivedi NB. Comparison of equatorial electrojet characteristics at Huancayo and Eusebio (Fortaleza) in the south American region. J Atmos Terr Phys 1982; 44: 785-92.

[35] Kane RP, Trivedi NB. Equatorial electrojet movements at Huancayo and Eusebio (Fortaleza) on selected quiet days. J Geomag Geoelect 1985; 37: 1-9.

[36] Shume EB, Denardini CM, de Paula ER, et al. Variabilities of the equatorial electrojet in Brazil and Peru. J Geophys Res 2010; 115 (A06306 doi:10.1029/2009JA014984).

[37] Rastogi RG. A new look at the ionospheric current system during I.G.Y. period. Indian J Radio Space Phys 2003: 32: 21-37.

[38] James ME, Rastogi RG, Chandra H. Day-to-day variations of geomagnetic $\mathrm{H}$ field and the equatorial ring current. J Indian Geophys Union 2008; 12: 69-78.

(C) Rastogi et al.; Licensee Bentham Open.

This is an open access article licensed under the terms of the Creative Commons Attribution Non-Commercial License (http: //creativecommons.org/licenses/by$\mathrm{nc} / 3.0 /$ ) which permits unrestricted, non-commercial use, distribution and reproduction in any medium, provided the work is properly cited. 